\title{
Effect of ouabain on Na,K-ATPase and electrolyte transport in the dog ileum in vivo
}

\author{
N. W. READ ${ }^{1}$, G. J. KREJS, V. E. JONES, AND J. S. FORDTRAN \\ From the Department of Internal Medicine, The University of Texas Health Science Center at Dallas, \\ Southwestern Medical School, Dallas, Texas, USA
}

SUMMARY It is currently believed that the rate and direction of sodium transport in the small intestine may be regulated by the activity of $\mathrm{Na}, \mathrm{K}$-ATPase in the basolateral cell membrane. We tested this hypothesis by selectively infusing ouabain, a known inhibitor of Na,K-ATPase, into the mesenteric artery supplying a perfused loop of ileum in 18 dogs. Before ouabain infusion there were significant correlations between the activity of $\mathrm{Na}, \mathrm{K}-\mathrm{ATPase}$ and net and lumen to plasma fluxes of sodium and chloride. After ouabain, there was no significant change in sodium and chloride transport, unidirectional fluxes or transmucosal potential difference, despite a $50 \%$ reduction in $\mathrm{Na}, \mathrm{K}$ ATPase activity. Furthermore, there was no significant correlation between Na,K-ATPase activity and sodium or chloride transport after ouabain. The only statistically significant effect of ouabain infusion was a reduction in the rate of bicarbonate secretion. Thus, the results of our experiments suggest that mucosal $\mathrm{Na}, \mathrm{K}-\mathrm{ATPase}$ is not a rate-limiting step in the absorption of sodium and chloride in the dog ileum, though it may be an important facilitative factor.

The normal small intestine in vivo usually absorbs physiological electrolyte solutions, although the rate of absorption is highly variable from subject to subject, and in the same subject on different days (Turnberg et al., 1970). In some apparently normal people and animals, the small intestine even secretes fluid, rather than absorbs it (Florey et al., 1941; Scott, 1965; Turnberg et al., 1970). In some animals, secretion is more common than absorption (Powell et al., 1968).

One of the plausible explanations of variable rates of absorption-secretion is the activity of the basolateral membrane concentration of sodium and potassium-dependent ATPase (Na,K-ATPase) (Schultz et al., 1974). This enzyme is believed to be the biochemical counterpart of a sodium pump, which transports sodium in exchange for potassium across the basolateral membrane (Hokin, 1976). It is postulated that the $\mathrm{Na}, \mathrm{K}-\mathrm{ATPa} e$ pumps more sodium out of the cell than potassium into the cell (Glynn et al., 1971; Rose and Schultz, 1971). Thus, this ATPase is thought (1) to cause a net transepithelial absorption of cations against an electrochemical gradient; (2) to cause the cellular concen-

${ }^{1}$ Address for correspondence: Dr N. W. Read, Department of Physiology, University of Sheffield, Sheffield S10 2TD, England.

Received for publication 30 November 1978 tration of sodium to be low and the cellular concentration of potassium to be high; and (3) to generate an electrical gradient (mucosa negative to serosa) across the intestinal epithelium (KoefoedJohnsen and Ussing, 1958; Schultz et al., 1974).

That the activity of this enzyme in the basolateral membrane might control the rate of intestinal absorption is suggested by several recent experiments. For example, the increase in sodium and water absorption in rat ileum produced by glucocorticoids is associated with increased activity of Na,K-ATPase (Charney et al., 1975; Charney and Donowitz, 1976). Furthermore, the increased sodium absorption and the raised transmucosal potential difference (PD) in the rat colon after corticosteroids are associated with an increase in the activity of Na,K-ATPase (Thompson and Edmonds, 1974; Charney et al., 1975).

If this enzyme is an important regulator of intestinal absorption, as these experiments suggest, then it follows that a reduction in its activity should be associated with a reduced rate of sodium absorption. Therefore, we designed experiments to study the effects of ouabain, an inhibitor of Na,K-ATPase, on the transport of electrolytes, the transmucosal PD, and the activity, of $\mathrm{Na}, \mathrm{K}-\mathrm{ATPase}$ in the dog ileum in vivo. To avoid systemic toxicity, ouabain was infused directly into the artery supplying the ileal loop. An abstract of this work has been presented to the 
British Society of Gastroenterology (Read et al., 1978).

\section{Methods}

\section{CONSTRUCTION OF LOOPS}

Experiments were carried out in 18 healthy, dewormed mongrel dogs weighing between 15 and 30 kg. The animals were fasted for 24 hours before surgery. Anaesthesia was administered with intravenous sodium pentobarbital, and respiration was controlled by means of a large volume animal respirator (model 613, Harvard Apparatus, Millis, Mass.). Laparotomy was performed, and a loop of ileum $25 \mathrm{~cm}$ in length was isolated between 15 and 40 $\mathrm{cm}$ proximal to the ileocaecal valve. Teflon spools, attached to wide bore polyethylene tubing (inside diameter $=4 \mathrm{~mm}$ ), were tied in place at the ends of the loop (Fig. 1). The gut adjacent to the loop was resected for at least $50 \mathrm{~cm}$ proximally and as far as the ascending colon distally. The remaining small intestine was drained externally through a Tefion spool and polyethylene tubing, while the proximal colon was closed.

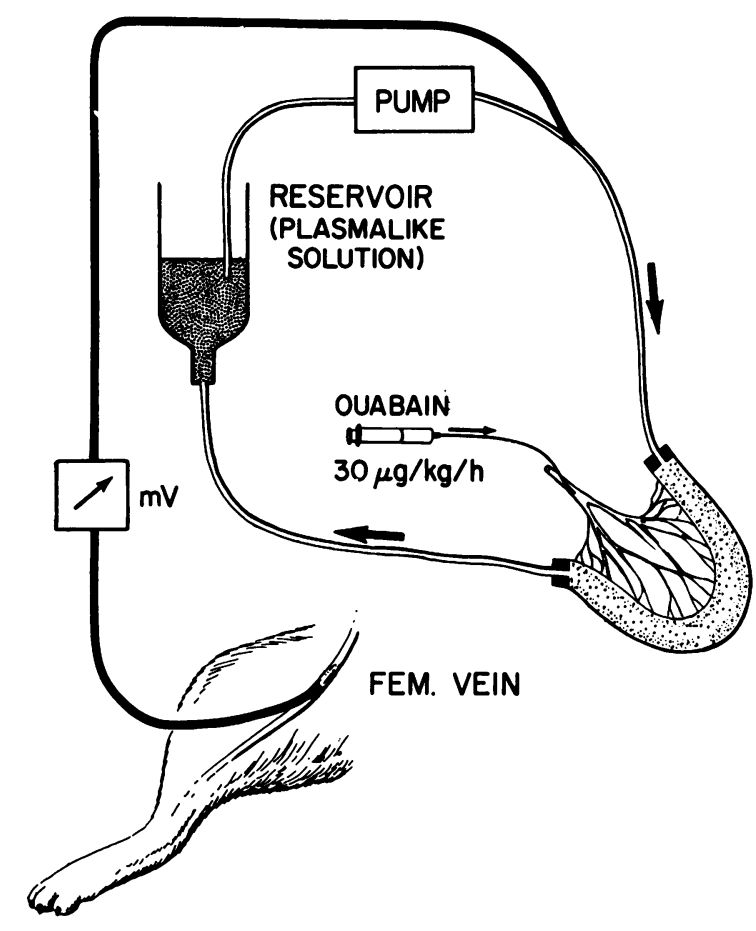

Fig. 1 Experimental design for in vivo perfusion of a loop of dog ileum and measurement of transmucosal potential difference $(P D)$. Ouabuin was infused via a fine catheter inserted into the main artery supplying the loop.
For selective arterial infusion of ouabain into the ileal loop, a fine polyethylene catheter (inside diameter $=0.011 \mathrm{~mm}$ ) was inserted through a distal arterial radical and advanced proximally until its tip was situated in the main trunk supplying the loop. The position of the catheter was ascertained by infusing bromosulphthalein (BSP $35 \mathrm{mg} / \mathrm{ml}$ ) at a constant rate $(0.76 \mathrm{ml} /$ minute $)$ by means of a Harvard pump (model 931, Harvard Apparatus, Millis, Mass.), and estimating the BSP concentration in samples taken from arteries (that had supplied the resected bowel) immediately proximal and distal to the loop, as well as from arteries supplying the remaining small bowel and ascending colon and from the femoral artery and femoral vein. If necessary, the position of the catheter was adjusted so that the concentration of BSP was high in the arteries immediately adjacent to the loop, but remained very low at the other sites. (The dilution of BSP reaching the arterial radicals immediately adjacent to the loop was also used to calculate the dose of ouabain reaching the loop.) Thereafter, the arterial catheter was used to infuse saline $(154 \mathrm{mM} \mathrm{NaCl})$ or a solution of ouabain in saline.

EXPERIMENTAL PROTOCOL

In all experiments, $175 \mathrm{ml}$ of an electrolyte solution $\left(\mathrm{Na}^{+}=135 \mathrm{mM}, \mathrm{K}^{+}=5 \mathrm{mM}, \mathrm{Cl}^{-}=115 \mathrm{mM}\right.$, and $\mathrm{HCO}_{3}{ }^{-}=25 \mathrm{mM}$, polyethylene glycol $=5 \mathrm{~g} / \mathrm{l}$, ${ }^{22} \mathrm{Na}=1 \mu \mathrm{Ci} / 1,{ }^{36} \mathrm{Cl}=1 \mu \mathrm{Ci} / 1, \mathrm{pH}=7 \cdot 4$, and osmolality $=275 \mathrm{mosmol} / \mathrm{kg}$ ) bubbled with a mixture of $95 \% \mathrm{O}_{2}$ and $5 \% \mathrm{CO}_{2}$ (yielding a $\mathrm{pCO}_{2}$ of about $40 \mathrm{~mm} \mathrm{Hg}$ ) was continuously recirculated (16 $\mathrm{ml} / \mathrm{min}$ ) through the loop from glass reservoirs (maintained at $38^{\circ} \mathrm{C}$ ) by means of a peristaltic pump (Desaga, Heidelberg). Intraluminal pressure in the loops was kept constant between 4 and $6 \mathrm{~cm}$ of $\mathrm{H}_{2} \mathrm{O}$ by adjusting the fluid level in the reservoir (Fig. 1). After an equilibration period of 15 minutes, an initial 12-ml sample of perfusate was removed for analysis. The perfusion was continued thereafter for a period of one hour before a final sample was withdrawn, and the loop was then drained. After the initial control period, ouabain was infused into the mesenteric artery at a constant rate for one hour, during which the loop was perfused continuously with the electrolyte solution. After ouabain infusion, a second one-hour perfusion period was carried out. Full thickness biopsies $(1.5 \mathrm{~cm} \times 1.5 \mathrm{~cm})$ were taken after the control period, after ouabain infusion and after the second perfusion period. After each biopsy, the intestinal defect was repaired by everting the mucosa and suturing the cut ends together. Haemostasis was secured before continuing the study.

In all experiments, arterial $\mathrm{pH}$ and $\mathrm{pCO}_{2}$ were 
monitored hourly, while serum concentrations of $\mathrm{Na}^{+}, \mathrm{K}^{+}$, and $\mathrm{Cl}^{-}$were determined in blood drawn at the beginning and end of each period. The ECG, arterial blood pressure and rectal temperature were monitored continuously. In order to prevent plasma volume depletion, sufficient Ringer's lactate solution was infused intravenously to maintain a diuresis of $20-40 \mathrm{ml} /$ hour. A thermal blanket and a heating lamp were used to maintain body temperature at $38^{\circ} \mathrm{C}$.

MEASUREMENT OF THE TRANSMUCOSAL POTENTIAL DIFFERENCE

The transmucosal PD was recorded using the method described previously (Read et al., 1977). Briefly, the perfusate itself acted as a flowing intraluminal electrode, while the reference electrode was the intravenous infusion of Ringer's lactate. These electrodes were connected via salt agar bridges $(2 \mathrm{M} \mathrm{KCl}$ in $3 \%$ agar) and balanced calomel half cells to the input terminals of a battery powered electrometer (model 602 , Keithley, Cleveland, Ohio), the output of which was displayed on a chart recorder (model B-261, Rikadenki Kogyo Co., Tokyo, Japan). The asymmetry of the recording system was determined at the beginning and end of each experiment and never exceeded $1 \mathrm{mV}$.

ANALYSIS OF PERFUSATE

Samples were analysed for polyethylene glycol (PEG) and electrolytes (Cooper et al., 1966), and the data were then used to calculate net electrolyte movements using methods previously described (Fordtran, 1966; Krejs et al., 1977). The total recovery of PEG was $97 \pm 1 \%$ during the control period and $98 \pm 1 \%$ after ouabain. Lumen to plasma unidirectional fluxes of $\mathrm{Na}^{+}$and $\mathrm{Cl}^{-}$were calculated using the equation described by Berger and Steele (1958). Samples of perfusate were also analysed for protein (Lowry et al., 1951), and the output of protein during each period was calculated and used as an index of mucosal integrity.

For statistical analysis, the results from the two perfusion periods were compared using the paired $t$ test.

ANALYSIS OF BIOPSY SAMPLES

Each specimen was washed thoroughly in ice cold isotonic saline and then scraped with a glass slide to remove the mucosa, which was then washed in ice cold saline and divided into two equal portions (120$220 \mathrm{mg}$ ). These were immersed briefly in ice cold buffer solution (pH 6.8) containing $130 \mathrm{mM} \mathrm{NaCl}, 5$ $\mathrm{mM} \mathrm{Na} 2$ EDTA and $30 \mathrm{mM}$ imidazole before being stored at $-70^{\circ} \mathrm{C}$. The samples were subsequently thawed and analysed for $\mathrm{Na}, \mathrm{K}$, and $\mathrm{Mg}$-ATPase activities by the method described by Charney et al.
(1974).

Briefly, the mucosal scrapings were homogenised by hand using iced Tenbroeck homogenisers filled with $4 \mathrm{ml}$ of the imidazole $\mathrm{Na}_{2}$ EDTA buffer solution containing $2.4 \mathrm{mM}$ sodium deoxycholate. The membrane-rich pellet obtained after successive centrifugations at $770 \mathrm{~g}$ and $10000 \mathrm{~g}$ for 10 minutes at $0^{\circ} \mathrm{C}$ was suspended in the homogenising solution without sodium deoxycholate. ATP hydrolysis was measured by incubating an aliquot of suspension containing approximately $100 \mu \mathrm{g}$ protein (Lowry et al., 1951) for 15 minutes at $37^{\circ} \mathrm{C}$ in a solution containing $100 \mathrm{mM} \mathrm{NaCl}, 20 \mathrm{mM} \mathrm{KCl}, 10 \mathrm{mM}$ imidazole, $5.4 \mathrm{mM} \mathrm{MgCl} 2$, and 5.4 mM disodium ATP (pH 7.6) and in a similar solution in which the $\mathrm{KCl}$ was omitted but the $\mathrm{NaCl}$ concentration was 120 $\mathrm{mM}$. The inorganic phosphate liberated was measured spectrophotometrically (Taussky and Shorr, 1953), and the enzyme activity was expressed as micromoles of inorganic phosphate $\left(\mathbf{P}_{\mathbf{i}}\right)$ liberated per $\mathrm{mg}$ protein per hour after a correction was made for nonenzymatic hydrolysis determined in blank tubes containing no tissue extract. The activity of $\mathrm{Na}, \mathrm{K}$ ATPase was calculated as the difference in activity between potassium-containing reactions (representing combined $\mathrm{Na}, \mathrm{K}-\mathrm{ATPase}$, and Mg-ATPase) and potassium-free reactions (representing only $\mathrm{Mg}$ ATPase activity).

Experiments were performed to compare activities of biopsies prepared from fresh tissue and assayed immediately with those of biopsies obtained at the same time, but then frozen for varying periods. Our results showed that biopsies could be preserved up to 120 days with no significant loss of Na,K-ATPase activity. As it was sometimes inconvenient to assay $\mathrm{Na}, \mathrm{K}-\mathrm{ATPase}$ on the same day, we routinely ran the assay 24-72 hours after each experiment.

\section{Results}

\section{DATA OBTAINED DURING CONTROL PERIOD}

\section{Transport rates}

Twelve of the 18 dogs absorbed sodium, while six secreted (Fig. 2). The mean result was absorption of $17 \mu \mathrm{mol} \mathrm{cm} .^{-1} \mathrm{~h}^{-1}$ (Table). Data for other measured electrolytes and for the unidirectional sodium and chloride fluxes are given in Fig. 2 and the Table.

\section{CORRELATION OF TRANSPORT RATE WITH} NA, K-ATPASE

There was a significant correlation between the $\mathrm{Na}, \mathrm{K}-\mathrm{ATPa}$ a activity and the net movement of sodium during the control period $(P<0.001$, $r=0.79$ ). As shown in Fig. 3, at activities above 20 units there was net absorption of sodium, whereas 


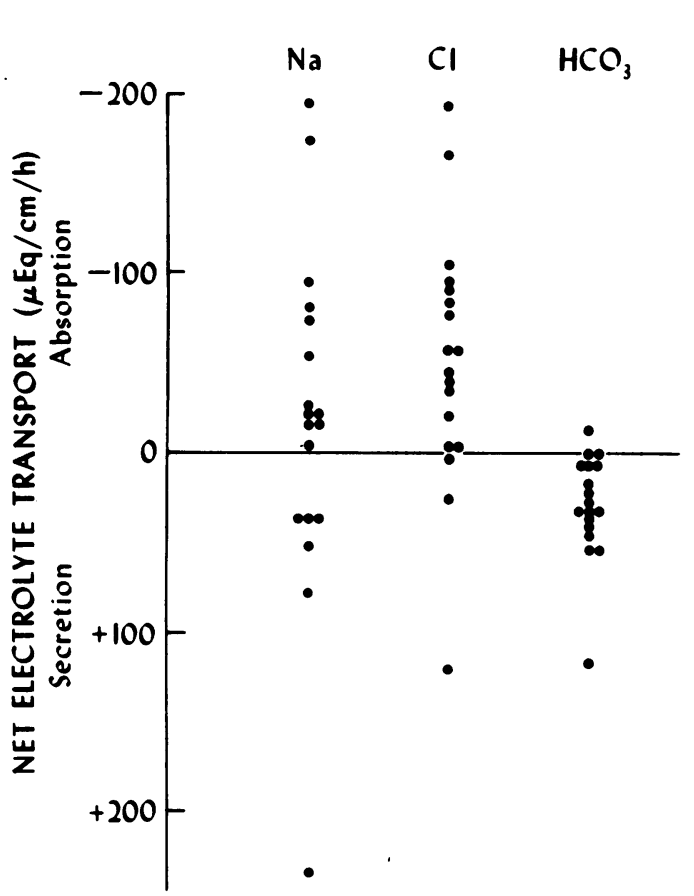

Fig. 2 The distribution of the next transport rates for sodium, chloride, and bicarbonate from the ileum of 18 dogs during the control period. For conversion to SI

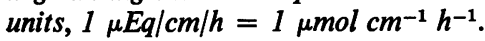

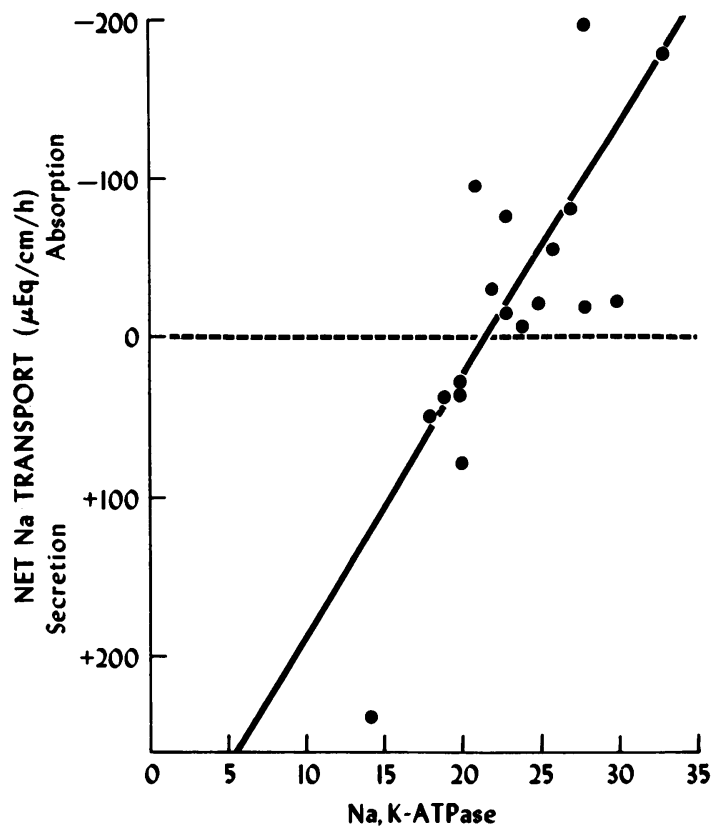

Fig. 3 Net sodium movement in each ileal loop during the control period plotted against mucosal $\mathrm{Na}, \mathrm{K}-\mathrm{ATPase}$ activity ( $\mu$ mol $P_{1}$ liberated $/ m^{\prime}$ protein $\left.{ }^{-1} / h^{-1}\right)$. Absorption is above the broken line and secretion below. The distribution of points suggests a significant correlation $(r=0.79, \mathrm{P}<0.001, n=18)$. For conversion to $S I$ units, $1 \mu \mathrm{Eq} / \mathrm{cm} / \mathrm{h}=1 \mu \mathrm{mol} \mathrm{cm} \mathrm{cm}^{-1} \mathrm{~h}^{-1}$.

Table Experimental data obtained during control period and after ouabain infusion (mean $\pm S E M$ )

\begin{tabular}{|c|c|c|c|}
\hline & Control & Post-ouabain & $\mathbf{P}$ \\
\hline 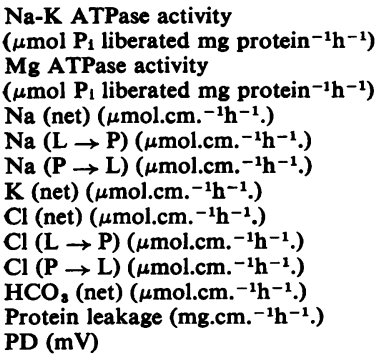 & $\begin{array}{r}23 \pm 1 \\
17 \pm 1 \\
-17 \pm 23 \\
-13 \pm \pm 18 \\
116 \pm 15 \\
+1 \pm 1 \\
-50 \pm 17 \\
104 \pm 15 \\
54 \pm 9 \\
+29 \pm 7 \\
1 \cdot 4 \pm 0.3 \\
-0.2 \pm 0.6\end{array}$ & $\begin{array}{r}12 \pm 1 \\
16 \pm 1 \\
-5 \pm 19 \\
144 \pm 26 \\
139 \pm 18 \\
+3 \pm 1 \\
-22 \pm 17 \\
118 \pm 18 \\
96 \pm 16 \\
+5 \pm 4 \\
2 \cdot 3 \pm 0 \cdot 6 \\
-0 \cdot 3 \pm 0.7\end{array}$ & $\begin{array}{l}<0.001 \\
>0.05 \\
>0.6 \\
>0.6 \\
>0.3 \\
>0.1 \\
>0.1 \\
>0.4 \\
>0.05 \\
<0.01 \\
>0.1 \\
>0.1\end{array}$ \\
\hline $\begin{array}{l}\text { Plasma electrolyte concentration } \\
\mathrm{Na}\left(\mathrm{mmol} . \mathrm{1}^{-1}\right) \\
\mathrm{Cl}\left(\mathrm{mmol} \mathrm{1}^{-1}\right) \\
\mathrm{K}\left(\mathrm{mmol} . \mathrm{1}^{-1}\right)\end{array}$ & $\begin{array}{ll}153 & \pm \\
114 \pm & 2 \\
4 \cdot 3 & \pm 0 \cdot 2\end{array}$ & 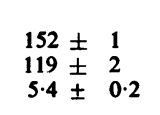 & $\begin{array}{l}>0.6 \\
<0.02 \\
<0.001\end{array}$ \\
\hline $\begin{array}{l}\text { Lumen electrolyte concentration } \\
\mathrm{Na}\left(\mathrm{mmol} . \mathrm{1}^{-1}\right) \\
\mathrm{Cl}\left(\mathrm{mmol} . \mathrm{1}^{-1}\right) \\
\mathrm{K}\left(\mathrm{mmol} . \mathrm{1}^{-1}\right)\end{array}$ & 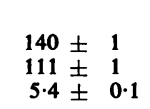 & 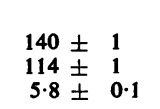 & $\begin{array}{l}>0.7 \\
<0.001 \\
<0.001\end{array}$ \\
\hline
\end{tabular}

For the net transport data, positive values indicate secretion, negative values absorption. The polarity of the PD is that of the lumen with respect to blood. The electrolyte concentrations are the mean of values obtained before and after each perfusion period. The $P$ values in the last column indicate the probability that the observed difference between data obtained during the control period and data obtained after ouabain infusion was due to chance alone. Statistically significant differences $(95 \%$ confidence limits) are in italic. 
below this value there was net sodium secretion. There were also significant correlations between $\mathrm{Na}, \mathrm{K}-\mathrm{ATPase}$ activity and net transport of chloride (P $<0.001, r=0.81)$, bicarbonate $(\mathrm{P}<0.01$, $r=0.57)$, and potassium $(\mathrm{P}<0.005, r=0.66)$. $\mathrm{Na}, \mathrm{K}-\mathrm{ATPase}$ activity was correlated with the unidirectional lumen to plasma flux of sodium $(P<0.001, r=0.71)$ and chloride $(P<0.001$, $r=0.72$ ), but not with the opposing plasma to lumen fluxes. There was no correlation between $\mathrm{Na}, \mathrm{K}$ ATPase activity and transmucosal PD.

There was no correlation between net transport or unidirectional fluxes of any measured electrolyte and the activity of Mg-ATPase.

\section{EFFECT OF OUABAIN}

\section{Preliminary experiments}

Ouabain was infused in three consecutive doses (10, 30 , and $50 \mu \mathrm{g} / \mathrm{kg} / \mathrm{h}$ ) into the artery supplying the ileal loop in three dogs. Each infusion lasted one hour and was separated from the next infusion by a gap of one hour, during which saline was infused into the mesenteric artery. Biopsies were taken for ATPase activity before, immediately after, and one hour after each ouabain infusion was discontinued. A dose of $10 \mu \mathrm{g} / \mathrm{kg} / \mathrm{h}$ produced a decline in Na,K-ATPase activity, but this recovered 60 minutes after the infusion. With $30 \mu \mathrm{g} / \mathrm{kg} / \mathrm{h}$, the activity of $\mathrm{Na}, \mathrm{K}$ ATPase fell but did not recover, while with $50 \mu \mathrm{g} / \mathrm{kg} / \mathrm{h}$ two of the dogs died shortly after the infusion as a result of cardiac arrhythmias. For all additional experiments, we used a dose of $30 \mu \mathrm{g} / \mathrm{kg} / \mathrm{h}$.

To decide when to carry out the test perfusion, we determined the Na,K-ATPase activity in biopsies taken at short intervals after starting the ouabain infusion in two dogs. In both animals there was an initial increase in Na,K-ATPase activity. After 30 minutes this fell below the initial value, reaching its lowest activity at one hour (Fig. 4). The activity of Mg-ATPase did not show any consistent decline during this period (Fig. 4).

Because Na,K-ATPase activity was not stable at any time during ouabain infusion, the $30-$ to 90 minute period after the completion of ouabain infusion was selected as the test period for measurement of ion transport.

\section{Results after ouabain infusion}

After infusion of ouabain $(30 \mu \mathrm{g} / \mathrm{kg} / \mathrm{h})$, the activity of Na,K-ATPase was reduced to $50 \%$ of the control value $(P<0.001)$ and remained at this level for at least three hours (Fig. 5). The activity of Mg-ATPase was unchanged by ouabain (Fig. 5).

Despite the profound and sustained reduction of $\mathrm{Na}, \mathrm{K}-\mathrm{ATPase}$, there was no significant change in the net or unidirectional lumen to plasma flux of sodium and chloride (Fig. 6 and the Table). This was true whether all animals were considered or whether only dogs who absorbed in the control period were considered. As shown in Fig. 6, the distribution of net absorption-secretion rates of sodium and chloride
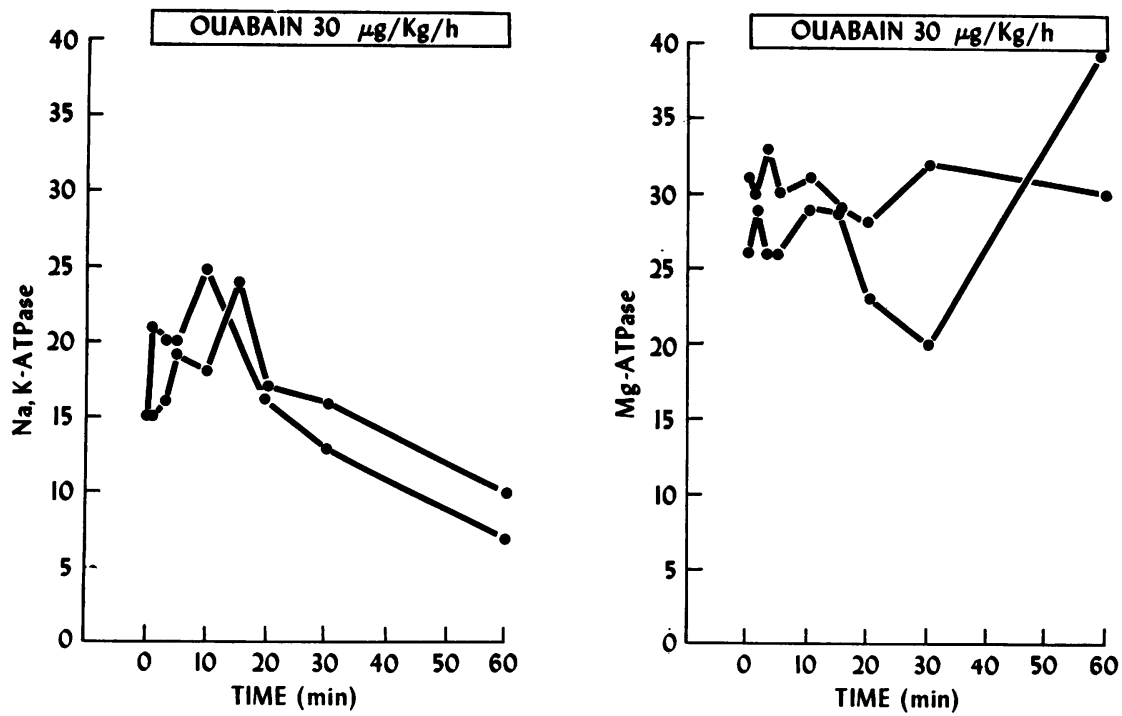

Fig. 4 Change in activity of $N a, K$-ATPase (left) and $M g$-ATPase (right) ( $\mu$ mol $P_{i}$ liberated/mg protein-1 $\left.\mathrm{h}^{-1}\right)$ in two dogs during infusion of $30 \mu \mathrm{g} / \mathrm{kg}$ ouabain over a period of one hour. Biopsies were taken before and at $1,3,5,10,15,20,30$, and 60 minutes after ouabain infusion. 

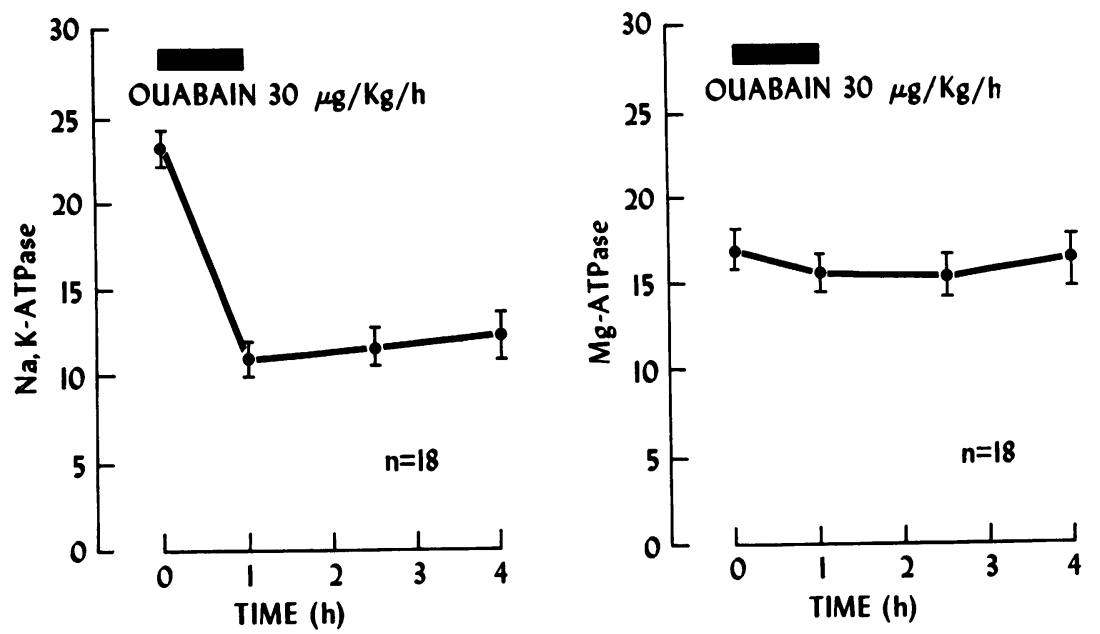

Fig. 5 The activity of Na,K-ATPase and Mg-ATPase ( $\mu$ mol $P_{i}$ liberated/mg protein ${ }^{-1} h^{-1}$ ) before and after infusion of ouabain $\left(30 \mu \mathrm{g} / \mathrm{kg}^{-1} \mathrm{~h}^{-1}\right)$. Results are mean $\pm S E M$ of 18 dogs.

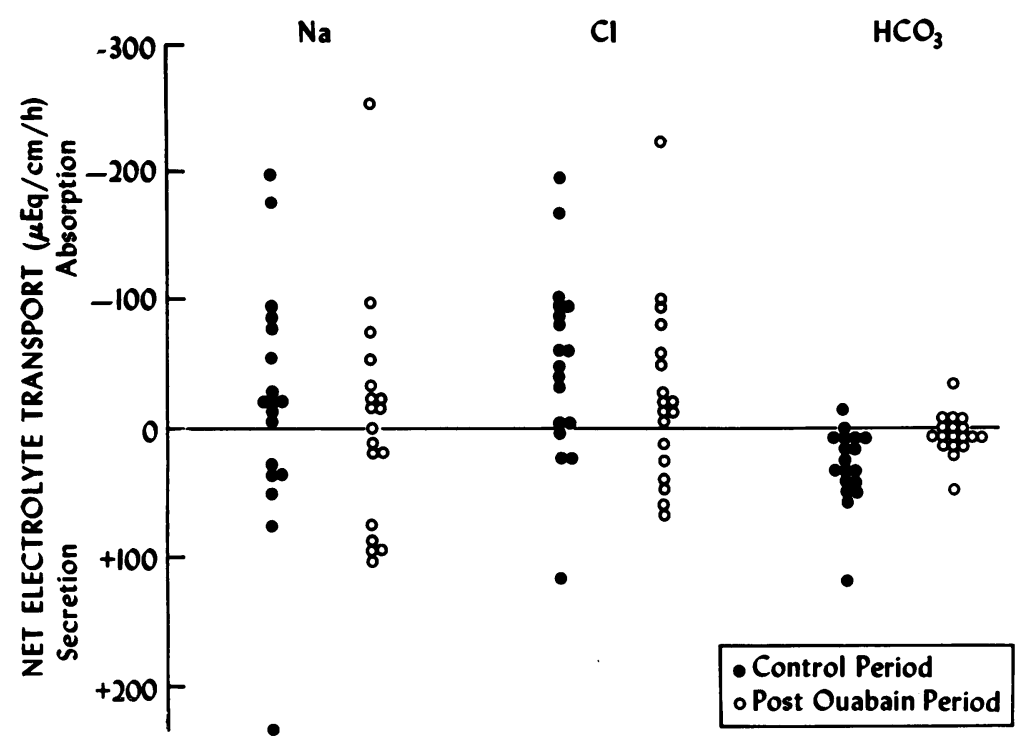

Fig. 6 A comparison of the distribution of the net transport rates for sodium, chloride, and bicarbonate from the ileum of 18 dogs during the control period (solid symbols) and in the test period after ouabain infusion (open symbols). For conversion to SI units, $1 \mu \mathrm{Eq} / \mathrm{cm} / \mathrm{h}=1 \mu \mathrm{mol}$ $c m^{-1} h^{-1}$.

were similar to those observed in the control period. However, ouabain infusion did result in a significant reduction in bicarbonate secretion $(P<0.01)$, as shown in the Table.

There was no significant difference between the PD during the perfusion period after ouabain compared with that recorded during the control period (Table). There was no significant change in the protein output from the loops before and after ouabain (Table), suggesting that the perfusion data after ouabain were not affected by any nonspecific toxic or ischaemic damage to the mucosa.

The mean concentration of ouabain reaching the loop was estimated indirectly by dividing the concentration of ouabain infused by a dilution factor, obtained by infusing BSP at a known concentration $(35 \mathrm{mg} / \mathrm{ml})$ and measuring its concentration in the arterial blood supplying the loop. Thus, assuming that there was no disappearance of ouabain or BSP from the plasma in the precapillary vascular bed we estimated that when ouabain was infused at a rate of $30 \mu \mathrm{g} / \mathrm{kg} / \mathrm{h}$ the mean concentration reaching the loop was $3 \times 10^{-7} \mathrm{M}$ (range 2 to $9 \times 10^{-7} \mathrm{M}$ ).

We could not detect any significant alteration in pulse rate, blood pressure, or ECG during or after local arterial infusion of ouabain. The $\mathrm{pH}$ and sodium 
concentration in peripheral blood also remained constant, although there were slight rises in plasma concentrations of potassium and chloride (Table) after ouabain infusion.

\section{Correlation of transport rates with Na,K-ATPase after ouabain infusion}

Unlike the findings in the control period, there were no significant correlations between Na,K-ATPase activity and net transport of sodium (Fig. 7), chloride, bicarbonate, or potassium after ouabain infusion. Inspection of Figs 3 and 7 shows that, in the control period, activities of $\mathrm{Na}, \mathrm{K}-\mathrm{ATPase}$ below 20 were associated with secretion of sodium, while, after ouabain, activities below 20 accompanied absorption of sodium as often as sodium secretion. In several dogs, relatively high rates of sodium absorption occurred in spite of relatively low concentrations of $\mathrm{Na}, \mathrm{K}-\mathrm{ATPase}$, and, in all instances where sodium was absorbed, the absorption was against both electrical and chemical gradients.

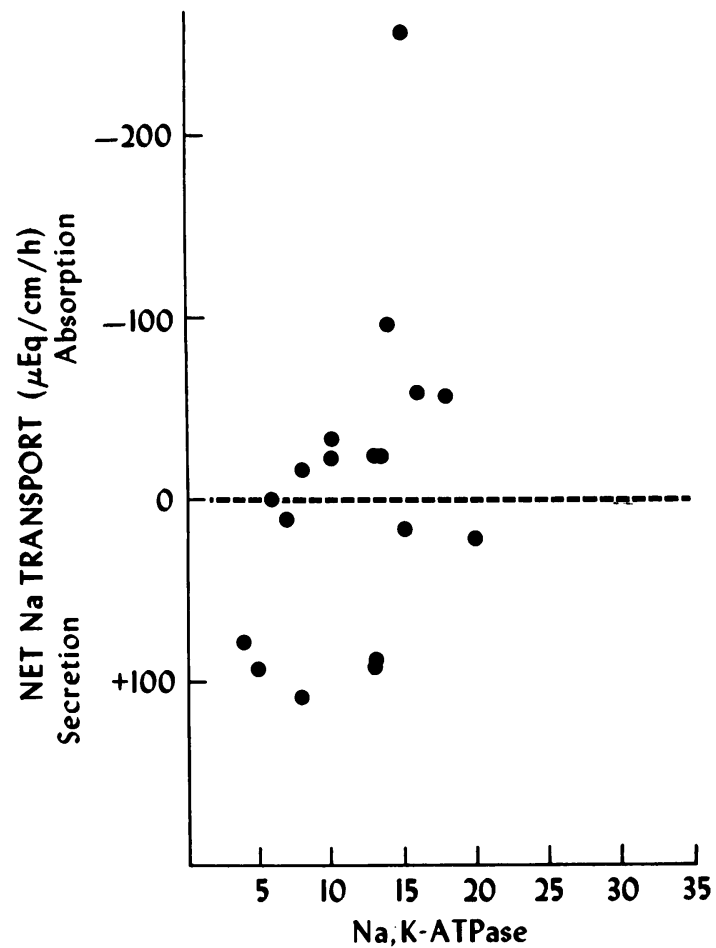

Fig. 7 Net sodium movement during the perfusion period after ouabain infusion plotted against mucosal activity of $\mathrm{Na}, \mathrm{K}-\mathrm{ATP}$ ase $\left(\mu \mathrm{mol} \mathrm{P}_{i}\right.$ liberated/mg protein ${ }^{-1}$ $h^{-1}$ ) in ileal loops from 18 dogs. Absorption is above the broken line, while secretion is below. Linear regression analysis revealed a correlation coefficient of 0.39 (P > 0.05). For conversion to SI units, $1 \mu \mathrm{Eq} / \mathrm{cm} / \mathrm{h}=$ $1 \mu \mathrm{mol} \mathrm{cm}^{-1} \mathrm{~h}^{-1}$.
There were no correlations in the post-ouabain period between $\mathrm{Na}, \mathrm{K}$-ATPase and the unidirectional fluxes of sodium or chloride.

\section{Discussion}

The results obtained in the control period demonstrate the problem which prompted these experiments. The ileal loops of these normal animals displayed a wide range of transport activity. Two-thirds of the animals absorbed sodium, and the rest secreted. The primary purpose of our experiments was to seek evidence bearing on the hypothesis (Charney and Donowitz, 1976) that the rate and direction of sodium movement in the intestine are determined by the activity of $\mathrm{Na}, \mathrm{K}-\mathrm{ATP}$ ase in the basolateral cell membrane.

The data obtained in the control period show a significant correlation between the activity of $\mathrm{Na}, \mathrm{K}$ ATPase and absorption of sodium and chloride. This is consistent with the hypothesis that Na,K-ATPase is a rate-limiting step in the absorption of salt from the ileum. Furthermore, since secretion was noted when the mucosal $\mathrm{Na}, \mathrm{K}-\mathrm{ATPase}$ activity was less than 20 , these results are also consistent with the notion that observed net transport rate is the sum of an absorptive function (usually ascribed to villous cells) and a secretory function (usually ascribed to the crypts) (Hendrix and Bayless, 1970). For example, it might be speculated from our control data that villous absorption is progressively reduced toward zero as ATPase falls, and that crypt secretion exceeds villous absorption when mucosal ATPase falls below 20 , resulting in an overall secretory mucosa.

However, before accepting a cause and effect relationship between mucosal $\mathrm{Na}, \mathrm{K}$-ATPase activity and net transport rate of sodium and chloride, it needs to be shown that an imposed reduction in $\mathrm{Na}, \mathrm{K}-\mathrm{ATPase}$ is associated with a fall in absorption rate or an enhanced secretion rate. To test this, we studied the changes in electrolyte transport caused by deliberately reducing the activity of $\mathrm{Na}, \mathrm{K}-\mathrm{ATPase}$ with ouabain. To avoid systemic toxicity, ouabain was administered selectively into an artery supplying the ileal loop in a dose which caused significant reduction of $\mathrm{Na}, \mathrm{K}-\mathrm{ATP}$ ase activity without causing obvious damage to the loop or cardiac arrhythmias. Using this method, we found that the activity of $\mathrm{Na}, \mathrm{K}-\mathrm{ATPase}$ was significantly and selectively reduced from a mean of 23 units to a value of 12 units after ouabain infusion. According to the relationship observed in the control period, such a reduction in $\mathrm{Na}, \mathrm{K}$-ATPase activity should be associated with profound secretion of sodium if $\mathrm{Na}, \mathrm{K}-\mathrm{ATPase}$ were the rate-limiting factor for sodium absorption. However, there was still a mean 
net sodium and chloride absorption from the ileal loops during the post-ouabain period, and the individual data showed a similar distribution of absorption-secretion rates to that in the control period (Fig. 6). The mean unidirectional sodium and chloride fluxes out of the lumen were also unchanged after ouabain infusion. Nine of the 18 ileal loops absorbed sodium in the post-ouabain period in spite of the reduction in Na,K-ATPase, and in each instance sodium absorption occurred against an electrochemical gradient. Moreover, unlike what obtained in the control period, there was no correlation after ouabain infusion between $\mathrm{Na}, \mathrm{K}$-ATPase activity and net or lumen to plasma unidirectional flux of sodium or chloride.

Experiments in vitro (Schultz and Zalusky, 1964) have shown that inhibition of sodium transport by ouabain is accompanied by a decrease in PD (lumen becoming less negative). In our present experiments, the PD was the same after ouabain infusion as it was before. Although changes in PD can arise from mechanisms other than electrogenic sodium absorption, these results nevertheless support our conclusion that ouabain did not decrease the activity of the transepithelial sodium pump.

Infusion of ouabain into the mesenteric artery in similar doses to those used in the present study has been shown to cause a reduction of mesenteric blood flow (Pawlik et al., 1974). Although we observed a slight pallor of the ileal loop during ouabain infusion (consistent with some reduction in blood flow), this had recovered completely by the beginning of the test perfusion; and there was no significant increase in protein output, which suggests that ouabain did not cause ischaemic damage to the mucosa. Moreover, it seems unlikely that our failure to show an effect of ouabain on electrolyte transport could be related to a transient decrease in blood flow, since a period of ischaemia in the canine small intestine is immediately followed by profound secretion of fluid and electrolytes (Mirkovitch and Menge, 1976). Indeed, it is remarkable that, despite the possibility of ischaemia together with considerable reduction in the activity of Na,K-ATPase, the ileal epithelium of half of the dogs absorbed sodium after ouabain infusion.

If we assume that a possible decrease in blood flow did not somehow facilitate absorption, then the only way to explain our findings that is still compatible with a rate-limiting role for $\mathrm{Na}, \mathrm{K}-\mathrm{ATP}$ ase is by invoking two $\mathrm{Na}, \mathrm{K}-\mathrm{ATPases}$, one subserving secretion and the other absorption. The inhibition of cholera-induced secretion by ouabain (Field, 1976) suggests the existence of a secretory Na,K-ATPase. If ouabain inhibits both absorption and secretory $\mathrm{Na}, \mathrm{K}-\mathrm{ATPases}$ in vivo, then the expected mean result in a number of loops would be little or no change in net sodium transport, but a significant reduction in the mean values for both unidirectional fluxes of sodium. In our experiments, however, there was no reduction in either the observed unidirectional flux of sodium out of the lumen or the calculated flux of sodium into the lumen. Thus, it is unlikely that the absence of a change in the net sodium transport after ouabain infusion can be explained by suppression of opposing $\mathrm{Na}, \mathrm{K}$-ATPases.

The only significant alteration in ion fluxes we observed after ouabain infusion was a reduction in bicarbonate secretion. The mechanism underlying this observation is open to speculation, but it might be somehow mediated by a change in intracellular sodium or potassium concentration.

In our opinion, the results of these experiments suggest that the mucosal activity of $\mathrm{Na}, \mathrm{K}-\mathrm{ATPase}$ is not a rate-limiting step in the absorption of sodium and chloride in the dog ileum. Our studies do not conclusively disprove such a role for this enzyme, since there may be several Na,K-ATPases within the intestinal epithelium, whereas only the basolateral membrane ATPase of the enterocyte is believed to be rate-limiting for salt absorption. However, we used essentially the same ATPase assay as previous workers whose results support the concept that $\mathrm{Na}, \mathrm{K}$ ATPase activity controls the rate of sodium absorption in the small intestine (Charney et al., 1975; Charney and Donowitz, 1976). Furthermore, most experts agree that the $\mathrm{Na}, \mathrm{K}-\mathrm{ATPase}$ method used in this experiment does in fact measure mainly the enzyme concentration of the basolateral membranes (Douglas et al., 1972; Fujita et al., 1972; Charney et al., 1974). It is possible, of course, that ouabain binds to sites other than $\mathrm{Na}, \mathrm{K}-\mathrm{ATPa} e$ during infusion in vivo and inhibits the enzyme only later during the homogenisation procedure. Although this could explain the lack of change in sodium transport during ouabain infusion, it seems an unlikely explanation, because ouabain entering the epithelial layer during infusion would be much more avidly and irreversibly bound to ATPase than to any other site. Moreover, if this were a valid criticism of our results, it would also apply to all other studies involving ouabain inhibition of ATPase, in vitro as well as in vivo.

Our conclusions are compatible with the recent experiments of Nellans and Schultz (1976), whose results suggest that in vitro the sodium-potassium exchange mechanism at the basolateral membrane functions independently of transepithelial sodium transport. Also, our data do not conflict with the observation that ouabain applied to in vitro gut preparations will inhibit sodium transport (Schultz and Zalusky, 1964), since the epithelium would appear to be exposed to a much higher ouabain concen- 
tration in the in vitro experiments than in the present study $\left(2 \times 10^{-4}\right.$ vs. $\left.3 \times 10^{-7} \mathrm{M}\right)$. For example, if there was a reduction in Na,K-ATPase of $100 \%$ in vitro but only $50 \%$ in vivo, the possible discrepancy would be resolved by postulating that $\mathrm{Na}, \mathrm{K}$-ATPase is an important facilitative factor for sodium absorption but not the rate-limiting step. Unfortunately, we are unaware of any in vitro study which measured the effect of ouabain on both transport and $\mathrm{Na}, \mathrm{K}-\mathrm{ATPase}$ activity concomitantly in intestinal mucosa.

Our results are in disagreement with a recent report that ouabain applied to the luminal surface of the mucosa reduced mucosal Na,K-ATPase by $32 \%$ and reduced absorption or caused secretion in the rabbit ileum in vivo (Charney and Donowitz, 1978). The explanation for this apparent discrepancy is unknown, but may be related either to the very high luminal concentrations of ouabain $(19.2 \mathrm{mM})$ used in that study, or to the possibility that different enzyme or transport systems may be affected when ouabain is delivered to the luminal rather than the serosal side of the epithelium, or to species differences.

If our conclusion that $\mathrm{Na}, \mathrm{K}-\mathrm{ATPase}$ is not a ratelimiting step for sodium and chloride absorption is correct, then the relationship between Na,K-ATPase activity and transport rate observed in the control period must either indicate that the sodium transport rate determines the level of basal Na,K-ATPase activity instead of the reverse, or that both sodium transport and basal Na,K-ATPase activity are regulated by some other, as yet undetermined, factor. By the same token, if our conclusions are correct, the rise in absorption rate after glucocorticoid hormones (Charney et al., 1975; Charney and Donowitz, 1976) cannot be taken as definitive evidence that $\mathrm{Na}, \mathrm{K}$ ATPase controls the rate of sodium absorption. In this respect, it is interesting that two groups of workers have observed that corticosteroids increased sodium transport and PD in the rat colon at a time when there was no detectable increase of $\mathrm{Na}, \mathrm{K}$ ATPase activity (Thompson and Edmonds, 1974; Binder, 1978).

It should be emphasised that our results do not argue against a role of $\mathrm{Na}, \mathrm{K}-\mathrm{ATPase}$ in mediating the coupled transport of sodium and potassium across the cell membrane (Hokin, 1976). Neither do they contradict the possibility that Na,K-ATPase may have an important or even a critical facilitative role in active absorption of sodium. The data do suggest that $\mathrm{Na}, \mathrm{K}-\mathrm{ATPase}$ is not the rate-limiting step for transepithelial sodium transport in dog ileum during perfusion of a balanced electrolyte solution.

The authors would like to express their appreciation to Dr Alan Charney for his advice and guidance in setting up the ATPase assay. They would also like to thank Jean Harber, Gertrud Krejs, Stephen Morawski, Dr Maria Read, and Carol Santa Ana for their expert assistance. This work was supported by United States Public Health Service Research Grant No. 5-RO1-AMO6506 from the National Institute of Arthritis, Metabolism and Digestive Diseases and the Southwestern Medical Foundation, Dallas, Texas. Dr Read was a recipient of a travel grant from the Wellcome Trust, London, England.

\section{References}

Berger, E. Y., and Steele, J. M. (1958). The calculation of transfer rates in two compartment systems not in dynamic equilibrium. Journal of General Physiology, 41, 1135-1152.

Binder, H. J. (1978). Effect of dexamethasone on electrolyte transport in the large intestine of the rat. Gastroenterology, 75, 212-217.

Charney, A. N., and Donowitz, M. (1976). Prevention and reversal of cholera enterotoxin-induced intestinal secretion by methyl-prednisolone induction of $\mathrm{Na}^{+}-\mathrm{K}^{+}$-ATPase. Journal of Clinical Investigation, 57, 1590-1599.

Charney, A. N., and Donowitz, M. (1978). Functional significance of intestinal $\mathrm{Na}^{+}-\mathrm{K}^{+}-\mathrm{ATPase}$ : in vivo ouabain inhibition. American Journal of Physiology, 234, E629E636.

Charney, A. N., Gots, R. E., and Giannella, R. A. (1974). $\left(\mathrm{Na}^{+}-\mathrm{K}^{+}\right)$-stimulated adenosine triphosphatase in isolated intestinal villus tip and crypt cells. Biochimica et Biophysica Acta, 367, 265-270.

Charney, A. N., Kinsey, M. D., Myers, L., Giannella, R. A., and Gots, R. E. (1975). $\mathrm{Na}^{+}-\mathrm{K}^{+}$-activated adenosine triphosphatase and intestinal electrolyte transport. Effect of adrenal steroids. Journal of Clinical Investigation, 56, 653660.

Cooper, H., Levitan, R., Fordtran, J. S.. and Ingelfinger, F. J. (1966). A method for studying absorption of water and solute from the human small intestine. Gastroenterology, 50, 1-7.

Douglas, A. P., Kerley, R., and Isselbacher, K. J. (1972). Preparation and characterization of the lateral and basal plasma membranes of the rat intestinal epithelial cell. Biochemical Journal, 128, 1329-1338.

Field, M. (1976). Regulation of active ion transport in the small intestine. In Acute Diarrhoea in Childhood, pp. 109127. Edited by K. Elliott and J. Knight. CIBA Foundation Symposium 42 (new series). Elsevier: Amsterdam.

Florey, H. W., Wright, R. D., and Jennings, M. A. (1941). The secretions of the intestine. Physiological Reviews, 21, 36-69.

Fordtran, J. S. (1966). Marker perfusion techniques for measuring intestinal absorption in man. Gastroenterology, 51, 1089-1093.

Fujita, M., Ohta, H., Kawai, K., Matsui, H., and Nakao, M. (1972). Differential isolation of microvillous and basolateral plasma membranes from intestinal mucosa.Mutually exclusive distribution of digestive enzymes and ouabain sensitive ATPase. Biochimica et Biophysica Acta, 274, 336347.

Glynn, I. M., Hoffman, J. F., and Lew, V. L. (1971). Some "partial reactions" of the sodium pump. Philosophical Transactions of the Royal Society of London B. Biological Science, 262, 91-102.

Hendrix, T. R., and Bayless, T. M. (1970). Digestion: 
Intestinal secretion. Annual Review of Physiology, 32, 139164.

Hokin, L. E. (1976). The molecular machine for driving the coupled transports of $\mathrm{Na}^{+}$and $\mathrm{K}^{+}$is an $\left(\mathrm{Na}^{+}+\mathrm{K}^{+}\right)$activated ATPase. Trends in Biochemical Sciences, 1, 233237.

Koefoed-Johnsen, V., and Ussing, H. H. (1958). The nature of the frog skin potential. Acta Physiologica Scandinavica, 42, 298-308.

Krejs, G. J., Seelig, L. L., Jr., and Fordtran, J. S. (1977). Effect of protonated 2,4,6-triaminopyrimidine, a "tight junction blocker", on intestinal transport in dog ileum in vivo. Gastroenterology, 72, 685-691.

Lowry, O. H., Rosebrough, N. J., Farr, A. L., and Randall, R. J. (1951). Protein measurement with the folin phenol reagent. Journal of Biological Chemistry, 193, 265-275.

Mirkovitch, V., and Menge, H. (1976). Movements of water and ions across dog ileal mucosa following ischemia or occlusion. In Intestinal Ion Transport, pp. 251-260. Edited by J. W. L. Robinson. MTP: Lancaster.

Nellans, H. N., and Schultz. S. G. (1976). Relations among transepithelial sodium transport, potassium exchange, and cell volume in rabbit ileum. Journal of General Physiology, 68, 441-463.

Pawlik, W., Shepherd, A. P., Mailman, D., and Jacobson, E. D. (1974). Effects of ouabain on intestinal oxygen consumption. Gastroenterology, 67, 100-106.

Powell, D. W., Malawer, S. J., and Plotkin, G. R. (1968). Secretion of electrolytes and water by the guinea pig small intestine in vivo. American Journal of Physiology, 215, 12261233.

Read, N. W., Smallwood, R. H., Levin, R. J., Holdsworth,
C. D., and Brown, B. H. (1977). Relationship between changes in intraluminal pressure and transmural potential difference in the human and canine jejunum in vivo. Gut, 18, 141-151.

Read, N. W., Krejs, G. J., Jones, V. E., and Fordtran, J. S. (1978). Effect of ouabain on Na-K-ATPase activity and electrolyte transport in the dog ileum (Abstract). Gut, 19, A440.

Rose, R. C., and Schultz, S. G. (1971). Studies on the electrical potential profile across rabbit ileum. Journal of General Physiology, 57, 639-663.

Schultz, S. G., Frizzell, R. A., and Nellans, H. N. (1974). Ion transport by mammalian small intestine. Annual Review of Physiology, 36, 51-91.

Schultz, S. G., and Zalusky, R. (1964). Ion transport in isolated rabbit ileum. I. Short-circuit current and Na fluxes. Journal of General Physiology, 47, 567-584.

Scott, D. (1965). Factors influencing the secretion and absorption of calcium and magnesium in the small intestine of the sheep. Quarterly Journal of Experimental Physiology, 50, 312-329.

Taussky, H. H., and Shorr, E. J. (1953). A microcolorimetric method for the determination of inorganic phosphorus. Journal of Biological Chemistry, 202, 675-685.

Thompson, B. D., and Edmonds, C. J. (1974). Aldosterone, sodium depletion and hypothyroidism on the ATPase activity of rat colonic epithelium. Journal of Endocrinology, 62, 489-496.

Turnberg, L. A., Bieberdorf, F. A., Morawski, S. G., and Fordtran, J. S. (1970). Interrelationships of chloride, bicarbonate, sodium, and hydrogen transport in the human ileum. Journal of Clinical Investigation, 49, 557-567 